\title{
Pediatric Headache: Ocular Approach
}

\author{
Abdullrahman JA* \\ Doctor of Optometry, Vision Eye Specialist Center, Saudi Arabia
}

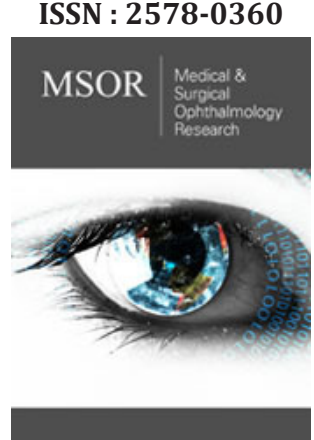

*Corresponding author: Abdulrahman JA, Doctor of Optometry, Vision Eye Specialist Center, Saudi Arabia

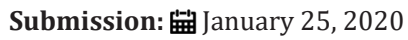

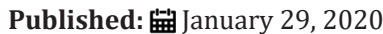

Volume 2 - Issue 5

How to cite this article: Abdulrahman JA. Pediatric Headache: Ocular Approach. Med Surg Ophthal Res. 2(5). MSOR.000550.2050.

DOI: 10.31031/MSOR.2020.02.000550

Copyright@ Abdulrahman JA, This article is distributed under the terms of the Creative Commons Attribution 4.0 International License, which permits unrestricted use and redistribution provided that the original author and source are credited.

\section{Opinion}

Headache is common in adolescents and children and it is a frequent reason to seek medical care for pediatric patients. The Global Burden of Disease study found that the headache disorders are the second-leading cause of disability globally in 2017 [1]. In children (age $<7$ years) headaches are slightly less common in young girls than boys but this ratio begins to change around the time of puberty, where the prevalence of headache is significantly lower in men than in women. In adolescence, $20 \%$ of boys and $27 \%$ of girls describe frequent or severe headaches, and $5 \%$ of boys and $8 \%$ of girls have had a migraine in the past year. In adults, over $60 \%$ of men and $80 \%$ of women have had a headache, and $6 \%$ of men and $15 \%$ of women report having had a migraine in the past year [2].

Headache disorders are classified into primary and secondary headaches. Primary headaches are further classified into migraine, Tension-type headache and cluster headache [3]. Migraine is common in pediatric patients, with a prevalence of $1 \%$ to $3 \%$ in children age 3 to 7 years and $8 \%$ to $23 \%$ in adolescence, when migraine is less common in boys than in girls. Migraine headaches with aura are less common than those without aura, but both can affect children. Other types of less common migraine headaches are basilar, confusional, and hemiplegic. Secondary headaches are classified into to ocular or non-ocular causes. Nonocular causes can be due to elevated ICP, Meningitis or encephalitis, Chiari I malformation, intracranial hemorrhage and posttraumatic headache [2].

Ocular causes of headache are Refractive error, Accommodative dysfunction, Binocular vision abnormalities and Ocular health. Regarding refractive errors, [4] in 2017, reported refractive errors represented $16.4 \%$ of the cases who presented with headache. Where the astigmatism was more frequent (65\%) followed by hypermetropia $(25 \%)$ and myopia (10\%) [4]. Accommodative dysfunctions such as insufficiency, infacility and spasm can cause headache. In accommodative insufficiency the AA is lower than expected for the patient's age. Those patients have a decreased PRA and usually fail the $+/-2.00 \mathrm{D}$ flipper test. Accommodative infacility patients report blurry vision at distance after prolonged near focusing and vice versa. Spasm of accommodation is spasm of Ciliary muscle that produces excess accommodation secondary to overstimulation of the parasympathetic nervous system, cholinergic drugs, trauma or MG. Those patients usually have impairment of distance vision and MEM lead. Binocular vision abnormalities include convergence insufficiency/excess, divergence insufficiency/excess, vergence insufficiency and vertical phoria [5]. In 2017, demonstrated other causes of headache; they found $3.96 \%$ patients with glaucoma, $0.53 \%$ with papilloedema and $5.80 \%$ with corneal ulcers [4].

\section{Conclusion}

In conclusion, it is very important to do comprehensive eye examination for patients present with headache to r/o ocular causes. Based on the previous studies, the majority of patients with headache had associated ocular causes..

\section{References}

1. Institute for Health Metrics and Evaluation (2018) Findings from the Global Burden of Disease Study 2017. Seattle, USA.

2. Blume HK (2012) Pediatric headache: A review. Pediatr Rev 33(12): 562-576. 
3. Dowson A (2015) The burden of headache: global and regional prevalence of headache and its impact. Int J Clin Pract Suppl 69(182): 3-7.

4. Fasih U, Shaikh A, Shaikh N (2017) Aetiology of headache in clinical ophthalmic practice at a tertiary care hospital of Karachi. J Pak Med Assoc 67(2): 166-170.
5. Cooper J (1998) Care of the patient with accommodative and vergence dysfunction. American Optometric Association, St Louis, Missouri.

For possible submissions Click below: 